\title{
High Performance Oil Resistant Rubber
}

\author{
A. I. Khalaf, A. A. Yehia, M. N. Ismail, S. H. El-Sabbagh \\ Department of Polymers and Pigments, National Research Center, Cairo, Egypt \\ Email: aman2502003@yahoo.com,nader_51@hotmail.com, salwa_elsabbagh@yahoo.com, ayehia1935@gmail.com
}

Received June 11, 2012; revised July 13, 2012; accepted July 25, 2012

\begin{abstract}
Blending of polymers has gained much interest due to the fact that, it can be used to produce new polymeric materials with specific properties suitable for some special applications. The blends from acrylonitrile butadiene rubber (NBR), chloroprene rubber (CR) and polyvinyl chloride (PVC) has been designed for products working in contact with oils. The characteristics of the designed blends either binary blends (NBR/PVC or PVC/CR) or ternary blends (NBR/ $\mathrm{PVC} / \mathrm{CR}$ ) were investigated by rheological properties, mechanical analysis and swelling in oil and toluene. It was found that the incorporation of $\mathrm{PVC}$ in the blend compositions leads to the decrease in degree of swelling, the penetration rate and the average diffusion coefficient. On the other hand the ultimate tensile strength (UTS), the hardness and strain energy were increased. This was attributed to the plastic nature of PVC, beside its additional behavior as filler. The crosslinking density in the blend vulcanizates under investigations was determined by Flory-Rehner and Mooney-Rivlin [Stress/Strain] equations. The higher values of crosslinking density determined by Mooney-Rivlin can be attributed to the additional physical crosslinks (e.g. entanglements etc), beside the chemical crosslinks determined by swelling in toluene. This study showed that NBR/PVC blends are characterized with high performance oil resistant, which can be recommended to automotive industry.
\end{abstract}

Keywords: Blends; NBR; PVC; CR; Oil Resistant; Thermal Ageing; Rheology; Strain Energy

\section{Introduction}

It is possible to get new materials with improved properties by blending elastomers and plastics. If the elastomer is the major phase and the plastic is the minor phase, this blend will have the properties of the reinforced elastomer. But if the plastic is the major phase, then the obtained blend will be toughened plastic material. One of the most common blends in modern science is polyvinyl chloride (PVC) with acrylonitrile butadiene rubber (NBR) [1,2]. The incorporation of PVC in NBR compounds generally improves the physico-mechanical and chemical properties and specially flame retardancy [3]. NBR/PVC blends can be conventionally milled, extruded, or compression molded using traditional processing equipments for natural and synthetic rubbers [4]. Due to the miscible nature of NBR/PVC blend, the soft blends of NBR/PVC can be categorized as a thermoplastic elastomer (TPE) and, more specifically, as a melt processable rubber [5]. Wimolmala et al. [6] blended (PVC) with NBR over a range of compositions ( $5 \mathrm{wt} \%$ to $40 \mathrm{wt} \%$ of rubber). The ultimate tensile stress (UTS) and modulus of the blends were found to decrease by increasing rubber content. The maximum tensile toughness was obtained for the blend with a rubber content of $30 \%$ at a blending temperature of $155^{\circ} \mathrm{C}$. Saha [7] studied the rheological and morpho- logical characteristics of PVC/CR blends. Experimental results showed that the chloroprene (CR) rubber can promote the processability and fusion of PVC.

Oil-resistant rubbers are special rubbers such as acrylonitrile butadiene rubber (NBR), chloroprene (CR) and polysulphide rubber. Oil-resistant polymeric materials are very important for the automotive industry, since a variety of spare parts may come into contact with oils and greases. The chemical composition of rubber and namely the electro-negativity and crystallinity plays the important role in the production of oil resistant products [8]. In NBR/PVC blends, the polar nature of NBR and PVC enhances the oil resistance of such blends $[9,10]$. Omran et al. studied different rubber blends based NBR and PVC and found that NBR/PVC blends had excellent engine and hydraulic oils resistance [11].

The present work is aiming to elaborate high performance oil resistant rubber products based on NBR, PVC and CR blends to be utilized in automobiles industry. The blend vulcanizates are evaluated by rheological, physical and mechanical characteristics.

\section{Experimental Work}

\section{Materials}

Acrylonitrile butadiene rubber (NBR) a Bayer AG prod- 
uct, Germany, perbunan N3310 with acrylonitrile content (\%) $34 \pm 1$, density $\mathrm{g} / \mathrm{cm}^{3}$ (0.99), Moony viscosity ML 4 $\left(100{ }^{\circ} \mathrm{C}\right) 65 \pm 7$.

Chloroprene rubber (CR), a Bayer AG product, Germany, Baypren110, Moony viscosity $\mathrm{ML} 4\left(100^{\circ} \mathrm{C}\right) 45$ 50 , density $\mathrm{g} / \mathrm{cm}^{3}$ (1.23).

Polyvinylchloride (PVC) powder, Suspension grade, with a K-value (65) and degree of polymerization 920 1060 was obtained from Sabic, Saudi Arabia.

High abrasion furnace black N330 (HAF), specific gravity $(1.78-1.82)$, PH value $(8-9.3)$, particle size (40 $\mathrm{nm})$, was obtained from Carbon black Company, Alex. Egypt.

Dioctylephthalate (DOP), sulphur, N-cyclohexyl-2-benzothiazole sulphonamide (CBS), N-isopropel-N-phenyl-p-phenylene diamine (IPPD), zinc oxide $(\mathrm{ZnO})$, magnesium oxide $(\mathrm{MgO})$, ethylene thiourea (ETU) and stearic acid were obtained from local rubber enterprises.

\section{Experimental Techniques}

\subsection{Blending and Mixing}

The blending of rubbers (NBR) and PVC was carried out according to ASTM D 15-72-2007 using Brabender plasticorder at $160^{\circ} \mathrm{C}$ with rotor speed $30-60 \mathrm{rpm}$. The compounding of the ingredients (Table 1) was carried out according to ASTM-D3182-2007 on a laboratory two- roll mill. The speed of the slow roll is $24 \mathrm{rev} / \mathrm{min}$, with a gear ratio of $1: 1.4$. The obtained compounds were left overnight before vulcanization. The vulcanization was carried out at $162^{\circ} \mathrm{C} \pm 1{ }^{\circ} \mathrm{C}$ for the pre-determined optimum cure time from Rheometric curves in an electrically heated press under a pressure of about $4 \mathrm{MPa}$ to get vulcanized rubber sheets of $2 \mathrm{~mm}$ thickness.

Table 1. Formulations and rheometric characteristics of rubber blends composition.

\begin{tabular}{cccccc}
\hline & 1 & 2 & 3 & 4 & 5 \\
\hline NBR & 100 & 100 & - & - & 100 \\
PVC & - & 20 & - & 20 & 20 \\
CR & - & - & 100 & 80 & 10 \\
St. acid & 1 & 1 & 1 & 1 & 1 \\
ZnO & 5 & 5 & 5 & 5 & 5 \\
MgO & - & - & 4 & 4 & 4 \\
DOP & 5 & 8 & - & 3 & 8 \\
HAF & 40 & 40 & 40 & 40 & 40 \\
CBS & 1.25 & 1.25 & - & - & 1.25 \\
S & 2 & 2 & - & - & 2 \\
IPPD & 1 & 1 & 1 & 1 & 1 \\
ETU & - & - & 1 & 1 & - \\
\hline \multicolumn{7}{c}{} & Rheometric characteristic at $162 \pm 1{ }^{\circ} \mathrm{C}$ & \\
\hline $\mathrm{M}_{\mathrm{L}}(\mathrm{dN} . \mathrm{m})$ & 7 & 6 & 8.5 & 6 & 7 \\
$\mathrm{M}_{\mathrm{H}}(\mathrm{dN} . \mathrm{m})$ & 71 & 69 & 61 & 40 & 59 \\
$\mathrm{Ts}_{2}$ (min.) & 1.875 & 2 & 1.25 & 1.9 & 1.75 \\
$\mathrm{Tc}_{90}(\mathrm{~min})$. & 10 & 15 & 20.75 & 25 & 22 \\
$\left.\mathrm{CRI}_{(\mathrm{min}}{ }^{-1}\right)$ & 12.3 & 7.69 & 5.12 & 4.32 & 4.93 \\
\hline
\end{tabular}

\subsection{Cure Characteristics}

$\mathrm{M}_{\mathrm{L}}$ (minimum Torque), $\mathrm{M}_{\mathrm{H}}$ (maximum Torque), $\mathrm{Tc}_{90}$ (optimum cure time), $\mathrm{Ts}_{2}$ (scorch time) and cure rate index (CRI) were determined according to ASTM-D 2084-2007 using a Monsanto (Akron, OH, USA) rheometer 100 at $162 \pm 1^{\circ} \mathrm{C}$.

\subsection{Mechanical Properties}

The tensile strength and elongation at break were determined at room temperature using tensile testing machine, Zwick 1425, according to ASTM-D412-2006.

The hardness was measured with shore A durometer according to ASTM-D2240-2007.

Thermal oxidative ageing was carried out according to ASTM-D73-94 at $90^{\circ} \mathrm{C}$ for 7 days.

\subsection{Equilibrium Swelling}

The equilibrium swelling of the blend vulcanizates was carried out according to ASTM D 573-2007. The equilibrium swelling $Q \%$ was calculated according to:

$$
Q \%=\left\{\left(w_{s}-w_{d}\right) / w_{d}\right\} \times 100
$$

where $w_{s}$ is the weight of the swelled specimen and $w_{d}$ is the weight of the dried specimen.

\subsection{Determination of Molecular Weight between Two Crosslinks $M_{c}$}

The swelling data were utilized to determine the molecular weight between two successive crosslinks $\left(M_{c}\right)$ by using Flory-Rehner relation ship $[12,13]$.

$$
M_{c}=\frac{-\rho V_{s} V^{1 / 3}}{\operatorname{In}\left(1-V_{r}\right)+V_{r}+\chi V_{r}^{2}}
$$

where $\rho$ is the density of rubber, $V_{s}$ is the molar volume of solvent (toluene), $V_{r}$ is the volume fraction of the swollen rubber, $\chi$ is the interaction parameter between the rubber and toluene.

The crosslinking density can be calculated from the equation:

$$
v=\left(1 / 2 M_{c}\right)
$$

\subsection{Determination of Strain-Energy}

Strain-energy values were obtained by plotting stress-strain values for vulcanized rubber and integrating the area under the curve up to the particular extension used. Simpson's rule [14] was applied to calculate the Strain-energy. The calculated strain-energy was plotted against the corresponding strain. This curve was used to obtain the strain-energy for particular extension. 


\subsection{Diffusivity}

Diffusivity [15] was calculated according to the following model.

$$
M_{t} / M_{\infty}=1-\left(8 / \pi^{2}\right)^{-\pi 2 D t / i 2}
$$

Where $M_{t}$ is the mass of the sample at time $t, M_{\infty}$ mass of the sample at infinite time, $I$ is the thickness of sample, $D$ diffusivity.

\section{Results and Discussion}

\subsection{Rheological Characteristics}

The formulations of the rubber compounds under investigation are given in Table 1 together with rheometric characteristics. It can be seen that the addition of $20 \mathrm{phr}$ of PVC to NBR or CR, decreases the minimum torque $\mathrm{M}_{\mathrm{L}}$ and maximum torque $\mathrm{M}_{\mathrm{H}}$. The decrease in torque values can be due to melting of PVC as the rheometer was operated at $162^{\circ} \mathrm{C}$. On the other hand, the cure time $\mathrm{Tc}_{90}$ is increased. This can be attributed to the dispersion of a part of the curing agents into PVC and as a result the efficiency of these curing agents is decreased and this is clear from the decrease of CRI data.

\subsection{Physico-Mechanical Characteristics}

The physico-mechanical properties of the rubber blends under investigation are determined at room temperature and are given in Table 2. It is clearly seen that the incorporation of PVC in either NBR or CR compounds leads to the increase of the modulus at $100 \%$ elongation, tensile strength, hardness and strain energy. This can be attributed to the creation of physical crosslinks on one hand and the presence of PVC domains (hard segments) in the rubber matrix. On the other hand such hard segments play the role of filler and consequently, the ultimate elongation is decreased. In other words, the toughness of the rubber vulcanizates generally decreases due to the incorporation of the plastic (PVC) in the rubber matrix [11].

\subsection{Thermal Oxidative Ageing}

NBR, CR and their blends with PVC were subjected to thermal ageing at $90^{\circ} \mathrm{C}$ for various time periods up to 7 days. The mechanical properties were measured and the retained values were calculated and are given in Table 3 . These data showed that the binary and the ternary blends have good retained values. The ageing resistance of the rubber blend is due to the presence of PVC in NBR and CR blends.

\subsection{Stress-Strain Behavior}

The stress-strain of the blend vulcanizates was determined
Table 2. Mechanical properties of the investigated formulation.

\begin{tabular}{lccccc}
\hline No. of samples property & 1 & 2 & 3 & 4 & 5 \\
\hline Modulus at 100\% (MPa) & 1.91 & 2.12 & 2.01 & 2.77 & 2.21 \\
Tensile strength (MPa) & 14.95 & 22.67 & 19.74 & 23.46 & 25.7 \\
Elongation at break (\%) & 526 & 425 & 455 & 350 & 390 \\
Young's modulus(MPa) & 1.78 & 1.84 & 1.59 & 2.11 & 1.89 \\
Hardness(shore A) & 67 & 69.5 & 70 & 74 & 71 \\
Strain energy MJ/m3 & 1.072 & 2.28 & 0.654 & 2.016 & 2.232 \\
\hline
\end{tabular}

Table 3. Retained values of investigated rubber vulcanizates.

\begin{tabular}{lccccc}
\hline Code No. & 1 & 2 & 3 & 4 & 5 \\
\hline $\begin{array}{l}\text { Tensile strength } \\
\text { before ageing, MPa }\end{array}$ & 14.95 & 22.67 & 19.74 & 23.46 & 25.7 \\
$\begin{array}{l}\text { Retained values of tensile } \\
\text { strength after 7 days, \% }\end{array}$ & 76.18 & 86.24 & 71.38 & 71.08 & 77.0 \\
$\begin{array}{l}\text { Elongation at break } \\
\text { before ageing, \% }\end{array}$ & 526 & 425 & 455 & 350 & 390 \\
$\begin{array}{l}\text { Retained values of } \\
\text { elongation at break after 7 } \\
\text { days, \% }\end{array}$ & 91 & 82 & 82 & 86 & 79 \\
\hline
\end{tabular}

and represented in Figure 1. It is clearly seen that at low strain the Young's moduli for all vulcanizates are practically equal and do not exceed than $2 \mathrm{Mpa}$, followed by the drawing stress region, where the strain increases, while the stress does not practically increase. Then after, the stress is sharp increased with the strain showing direct proportionality as the curves seem to be straight lines. These data ensure the behavior of PVC as additional filler as previously stated and shown in Table 2 . The other contribution that arises from incorporation of PVC into rubber is the formation of filler-rubber interaction, leading to additional physical crosslinks in the network structure of the blends. Consequently, the energy absorbed per unit volume $(W)$ is expected to increase in the deformed rubber blends. Thus the energy absorbed can be written as:

$$
W=f \sigma(\varepsilon) \mathrm{d} \varepsilon
$$

Where $\sigma$ is stress as a function of the strain $\varepsilon$. Therefore the higher the area under the stress-strain curve, the higher the energy absorption capacity. The NBR and CR have the lowest area under the stress-strain curves and consequently, they have the lowest energy absorption. On the other hand, the NBR/PVC, NBR/ $\mathrm{PVC} / \mathrm{CR}$ and $\mathrm{CR} / \mathrm{PVC}$ have the highest absorption of energy. These findings are in a good agreement with the data of presented in Table 2, which showed the increase in the strain energy due to the incorporation of PVC in NBR and CR rubbers.

\subsection{Swelling Studies}

The swelling characteristics of the rubber blends in tolu- 
ene and oil are shown in Table 4. The percentage of oil and toluene uptake was considerably decreased after the addition of PVC to rubber. This can be attributed to the fact that the presence of PVC in the NBR/PVC or $\mathrm{CR} / \mathrm{PVC}$ matrices restricts the penetration of oil as well as the solvents into the intermolecular spaces and hence decreases the swelling percentage [16]. Besides, the polarity nature of the pristine polymers.

\subsection{Model of Swelling of Rubber/PVC Blends}

From previous studies [16-19], it was found that, the oil immersion of rubber/PVC blend compounds, the oil molecules must penetrate in the rubber phase and go around the PVC phase. This is schematically illustrated in Figure 2. This illustration describes how the dispersion of the PVC phase could affect the swelling process of rubber/PVC blends. The dispersed PVC phase could lead to a very-tortuous path for oil molecules traveling through the blend matrix. This behavior is similar to that between mechanical and transport properties of two-phase system and the permeation models of composite materials [18]. The weight increase (oil uptake) by the rubber/PVC blends immersed in oil may be approximately represented by the following equation:

$$
\begin{gathered}
\Delta W_{\text {Blend }}=\frac{\phi_{\text {rubber }} \Delta W_{\text {rubber }}}{1+N / 2\left(\phi_{\text {PVC }}\right)} \\
\Delta W_{\text {rubber }}=\frac{W-W_{0}}{W_{0}}
\end{gathered}
$$

$W$ is the weight of rubber specimen after a certain time period of immersion and $W_{0}$ is the initial weight before immersion. $\phi_{\text {rubber }}$ and $\phi_{\mathrm{PVC}}$ are the volume fractions of rubber and PVC. The volume fraction of polymer $\phi$ was being calculated by the following equation:

$$
1 / \Phi=1+\left(W_{s} \rho_{r} / W_{i} \rho_{s}\right)
$$

where $W_{i}$ and $W_{s}$ are the weight of rubber sample in air and in the swollen state respectively, $\rho_{s}$ and $\rho_{r}$ are the densities of the solvent and the rubber respectively.

$\Delta W_{\text {rubber }}$ is the percentage of the weight increase of the rubber alone, after a certain time period of immersion, and $N$ is a parameter related to the oil-molecule diffusion path and state of dispersion of the PVC phase.

This equation implies that, if the dispersed PVC phase is spherical in shape, then $N=1$. Therefore it is quite inefficient in decreasing oil swelling. On the other hand, if the dispersed PVC phase is oval or elongated PVC phase, then $N>1$. Since the rubber sheets are usually formed by passing out through two roll mill. This could lead to the orientation of the PVC phase to the most elongated shape. Consequently, the oil uptake by the blends would be decreased. When the increase in weight of the specimen immersed in the oil $\Delta W_{\text {rubber }}$ is plotted against the ageing time, a curve linear line results as depicted in Figure 3. The results indicate that the oil swelling has been decreased by the ageing time. On the other hand the presence of tortuous effect cause the impenetrable PVC phase increase the diffusion path length of the oil molecule in the rubber matrix and also reduce the cross-sectional area of the rubber matrix available for the penetration of oil molecules [18].

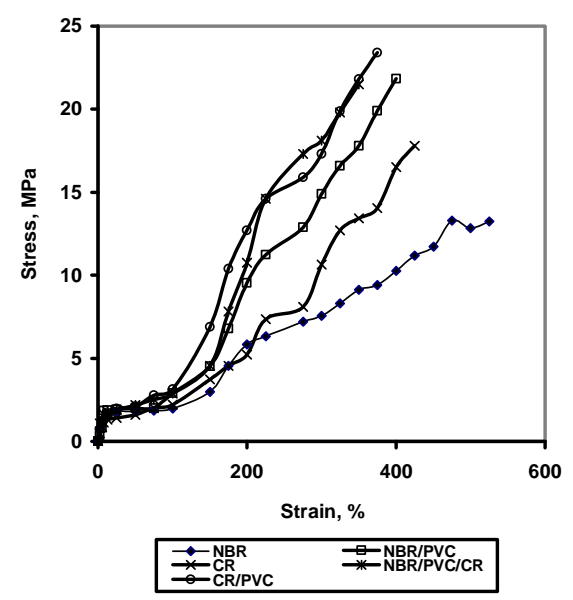

Figure 1. Strain curves for investigated vulcanizates.

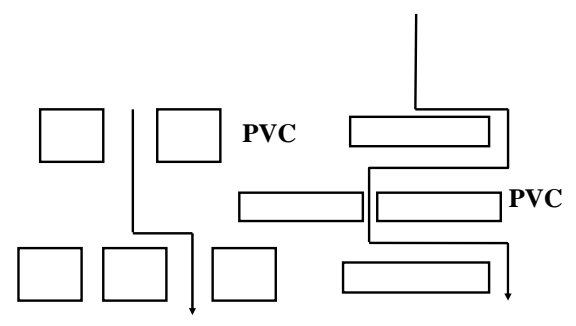

Figure 2. Schematic illustration of the diffusion pathway for oil in rubber having PVC phases of various geometries.

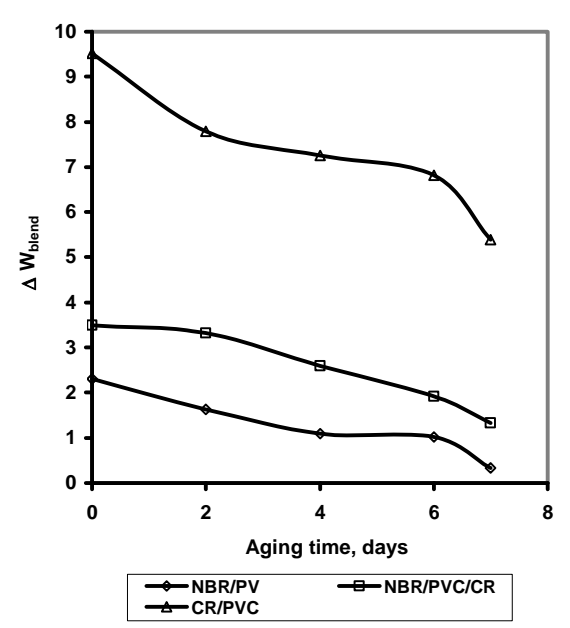

Figure 3. Percent weight increase of investigated $\Delta \boldsymbol{W}_{\text {blend }}$ blends, as a function of aging time; immersion in oil. 


\subsection{Effect of PVC on Diffusivity}

The diffusion in rubber is important, because it is always used in contact with foreign molecules, which may be gases, liquids, or solids. The study of diffusion of oils or organic solvents in rubber products is very serious from scientific and economic points of view. The oil resistant rubbers are important in automotive industry. Oil resistance is the reciprocal of the degree of swelling in oil and is governed by the competition between the driving force towards dissolution of the rubber in the low-molecularweight oils and the intermolecular forces of the polymer matrix. Diffusivity of oil in rubber (NBR or CR) or rubber/PVC blends were determined according to the following model [11].

$$
M_{t} / M_{\infty}=1-\left(8 / \pi^{2}\right) e^{-\pi 2 D t /} l^{2}
$$

Where $M_{t}$ is the mass of the sample at time t, $M_{\infty}$ mass of the sample at infinite time, $I$ is the the thickness of sample, $D$ diffusivity.

Let

$$
\begin{gathered}
M_{t} / M_{\infty}=X \\
\ln (1-x)=\ln \left(8 / \pi^{2}\right)-\pi^{2} D t / l^{2}
\end{gathered}
$$

By plotting $\ln (1-x)$ versus $(t)$, the diffusivity $(D)$ can be calculated from the slope $\left(-\pi^{2} D t / l^{2}\right)$. Figure 4 represents the plot of $\ln (1-x)$ versus $t$, from which, the diffusivity values are calculated and are given in Table 4 . As noticed from these values, the addition of PVC to rubber leads to the decrease of the diffusivity of oil in rubber. The diffusivity in NBR/PVC is less than the diffusivity in $\mathrm{CR} / \mathrm{PVC}$. This can be attributed to the difference in polarity, since $\mathrm{C} \equiv \mathrm{N}$ group is more electron withdrawing than $\mathrm{Cl}$ atom. Consequently, the presence of polar groups is believed to be responsible for the observed good oil resistance [20,21].

\section{Crosslink Density Measurements}

The equilibrium swelling in toluene of the vulcanizates were determined in order to evaluate the extent of crosslinking. The swelling values are given in Table 4. One can see, as the equilibrium swelling values decrease, the degree of crosslinking increase. It is clear also that the addition of PVC to rubbers noticeably decreases the values of equilibrium swelling.

In order to study the effect of PVC on the crosslink density of the NBR or CR vulcanizates, considering the PVC as additional filler. The calculations were made according to Mooney-Rivlin equation [13,22-23].

$$
V=\frac{F}{2 A_{0} \rho R T\left(\lambda-\lambda^{-2}\right)}
$$

Where $V$ is the effective crosslink density, $F$ is the force, $A_{0}$ is the area of cross section, $R$ is the gas constant, $T$

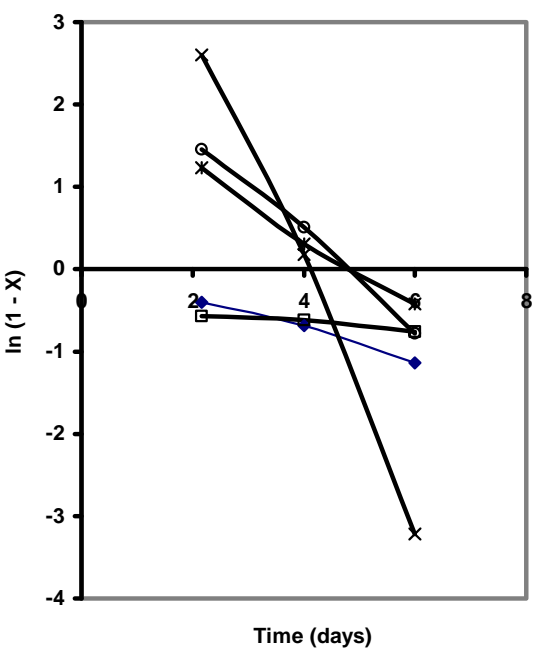

\begin{tabular}{|c|c|c|c|c|c|}
\hline No. of samples property & 1 & 2 & 3 & 4 & 5 \\
\hline Swelling index & 2.18 & 2.06 & 2.8 & 2.34 & 2.48 \\
\hline $\begin{array}{l}\text { Equilibrium swelling in } \\
\text { toluene, } \%\end{array}$ & 126 & 121 & 202 & 149 & 145 \\
\hline Soluble fraction, $\%$ & 4.09 & 7.98 & 7.22 & 5.29 & 7 \\
\hline Swelling in oil & 0.3 & 0.2079 & 0.81 & 0.86 & 0.528 \\
\hline $\begin{array}{l}\text { Crosslink density from } \\
\text { swelling(vx104) mole/cc }\end{array}$ & 4.79 & 4.95 & 4.05 & 4.5 & 5.29 \\
\hline $\begin{array}{l}\text { Crosslink density from } \\
\text { stress-strain (vx104) } \\
\text { mole/cc }\end{array}$ & 8.46 & 9.18 & 12.9 & 14.92 & 18.67 \\
\hline $\begin{array}{l}\text { Molecular weight } \\
\text { between crosslinking, } \\
\mathrm{g} / \mathrm{mol}\end{array}$ & 1044 & 1010 & 1235 & 1111 & 945 \\
\hline Diffusivity, mm/day & 0.0194 & 0.0051 & 0.0215 & -0.1537 & -0.0546 \\
\hline
\end{tabular}

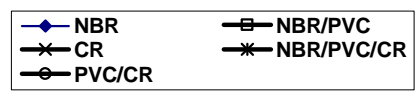

Figure 4. Plote of In (1-X) versus $T$.

Table 4. Network characterization.

is the absolute temperature and $\lambda$ is the extension ratio of the sample.

The calculated amounts of crosslinks $v$ are given Table 4. It can be seen that crosslink density values follow similar trends in both types of measurements (swelling and stress-strain). The higher values of crosslinking density $V$ determined by Mooney-Rivlin can be attributed to the additional physical crosslinks e.g. entanglements, Hydrogen bonds and polar-polar inter action [24,25], beside the chemical crosslinks determined by swelling in toluene.

\section{Conclusions}

Based on the present studies, the main conclusions are:

1) The elaborated blends are characterized with high performance oil resistant, which can be recommended to 
automotive industry.

2) The addition of PVC to rubber (NBR or CR) increase the optimum cures time.

3) Tensile strength, modulus, hardness and strain energy of NBR and CR were improved by the addition of PVC.

4) The crosslink densities of the rubber vulcanizates calculated by the swelling data are slightly lower than that calculated by stress-strain measurements. This deference was due to the additional physical crosslinks (eg. entanglements, polarity interactions etc).

5) The vulcanizates containing PVC showed improved thermal ageing resistance in comparison with vulcanizates without PVC. The thermal ageing resistance of the vulcanizates can be arranged as:

$\mathrm{NBR} / \mathrm{PVC}>\mathrm{NBR} / \mathrm{PVC} / \mathrm{CR}>\mathrm{CR} / \mathrm{PVC}$.

\section{REFERENCES}

[1] K. R. Habeab, G. Unnikrishnan, A. Sujith and C. K. Radhakrishnan, "Cure Characteristics and Mechanical Properties of Styrene-Butadiene Rubber/Acrylonitrile Butadiene Rubber," Materials Letters, Vol. 59, No. 6, 2005, pp. 633-639. doi:10.1016/j.matlet.2004.10.050

[2] B. M. Walker and C. P. Rader, "Handbook of Thermoplastic Elastomer," Van Nostrand Reinhold, New York, 1988. doi:10.1007/978-1-4613-1671-8

[3] A. Mousa, U. S. Iskiaku and Z. A. Mohd Ishak, "The Effect of Prolonged Thermo-Oxidative Ageing on the Mechanical Properties of Dynamically Vulcanized Poly (Vinyl Chloride)/Nitrile Butadiene Rubber Thermoplastic Elastomers," International Journal of polymeric materials, Vol. 55, No. 4, 2005, pp. 235-253. doi:10.1080/009140390927303

[4] A. H. Mazumdar and M. S. Majumdar, "Rubber Handbook," Synthetics and Chemicals Ltd., Bomboy, 1983.

[5] S. Krause, "Polymer Blends," Academic press, New York, 1978.

[6] E. Wimolmala, J. Woothikanokkhan and N. sombatsompop, "Effects of Composition and Temperature on Extrudate Characteristics, Morphology, and Tensile Properties of Acrylic Rubber-Blended PVC," Journal of Applied Polymer Science, Vol. 80, No. 13, 2001, pp. 2523-2534. doi:10.1002/app.1361

[7] S. Saha, "Rheological and Morphological Characteristics of Polyvinylchloride/Polychloroprene Blends-Effect of Temperature and Mixing Speed," European Polymer Journal, Vol. 37, No. 2, 2001, pp. 399-410. doi:10.1016/S0014-3057(00)00019-7

[8] J. R. Fried, "Polymer Science and Technology," Prentice Hall, Upper Saddle River, 1995.

[9] H. Ismail and A. M. M. Yusof Supri, "Blend of Waste Poly(vinylchloride) (PVCw)/acrylonitrile Butadiene-Rubber (NBR): The Effect of Maleic Anhydride (MAH)," Polymer Testing, Vol. 23, No. 6, 2004, pp. 675-683. doi:10.1016/j.polymertesting.2004.01.008
[10] K. E. Goorge, "Blends and Alloys," Chapman and Hall, London, 1993.

[11] A. M. Omran, A. M. Youssef, M. M. Ahmed and E. M. Abdel Bary, Kautch Gummi Kunst, Vol. 6, 2010, pp. 197-202.

[12] P. P. Flory, "Principles of Polymer Chemistry," Cornell University, Ithaca, 1953.

[13] M. N. Ismail and A. I. Khalaf, "Styrene-Butadiene Rubber/Graphite Powder Composites: Rheometrical, Physicomechanical, and Morphological Properties," Journal of Applied Polymer Science, Vol. 120, No. 1, 2011, pp. 298-304. doi:10.1002/app.33101

[14] R. S. Rivlin and A. G. Thomas, "Rupture of Rubber. I. Characteristic Energy for Tearing," Journal of Polymer Science, Vol. 10, No. 3, 1953, pp. 291-318. doi:10.1002/pol.1953.120100303

[15] G. A. Zhang, M. L. Zhou, J. H. Ma and B. R. Liang, "Preparation and Swelling Properties of Solution Crosslinked Poly(cis-1,4-butadiene) Gels," Journal of Applied Polymer Science, Vol. 90, No. 8, 2003, pp. 2241-2245. doi:10.1002/app.12888

[16] A. Mousa, U. S. Ishiaku and Z. A. Mohd Ishak, "Oil Resistance of Dynamically Vulcanized Poly(Vinyl Chloride)/Nitrile Butadiene Rubber Thermoplastic Elastomers," Polymer Bulletin, Vol. 53, No. 3, 2005, pp. 203-212. doi:10.1007/s00289-004-0325-6

[17] B.-L. Lee, "Multiphase Polymer Processing: ControlledIngredient-Distribution Mixing and Its Effect on Some Properties of Styrene-Butadiene (SBR)/Butadiene-Acrylonitrile Copolymer Rubber Blend Compounds," Polymer Engineering and Science, Vol. 22, No. 14, 1982, pp. 902911.

[18] A. A. Shokri, G. Bakhshandeh and T. D. Farahani, Irainan Polymer Journal, Vol. 15, 2006, pp. 227-237.

[19] M. Abdul Kader and A. K. Bhowmick, "Polymer Degradation and Stability," Elsevier, Vol. 79, No. 2, 2003, pp. 283-295. doi:10.1016/S0141-3910(02)00292-6

[20] M. F. Myntti, "Comparing Fuel and Oil Resistance Properties," Rubber World, Vol. 228, No. 3, 2003, pp. 38-41.

[21] N. Z. Norman, H. Ismail and A. A. Rashid, "Characterization of Styrene Butadiene Rubber/Recycled Acrylonitrile-Butadiene Rubber (SBR/NBRr) Blen," Polymer Testing, Vol. 29, 2010, pp. 200-208. doi:10.1016/j.polymertesting.2009.11.002

[22] S. S. Hamza, S. El-Sabbagh and F. shokr, "Elastic Behavior of NR/IIR Rubber Blend Loaded with Different Compatibilizers," International Journal of Polymeric Materials, Vol. 57, No. 3, 2008, pp. 203-215. doi:10.1080/00914030701413330

[23] R. S. Rivlin, "The Elasticity of Rubber," Rubber Chemistry and Technology, Vol. 65, 1992, pp. G51-G66. doi: $10.5254 / 1.3538628$

[24] A. S. Aprem and S. Thomas, Journal of Elastomer and plastics, Vol. 35, 2003, pp. 29-55.

[25] D. S. Campbell and A. V. Chapman, "Natural Rubber Research," Journal of Natural Rubber Research, Vol. 5, No. 4, 1990, pp. 246-258. 